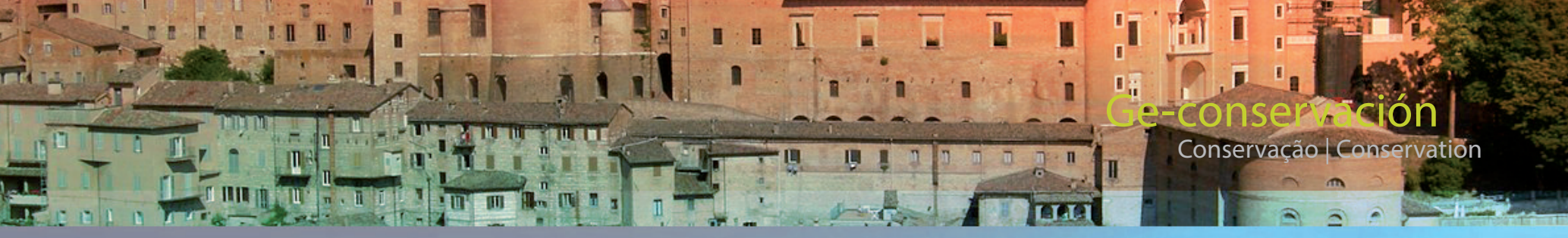

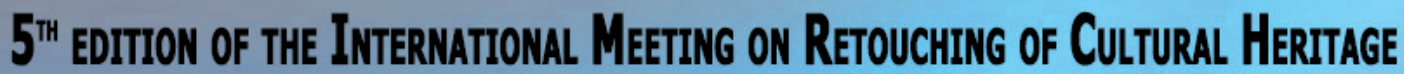 Univeranià degli Studor di Urbino "Carlo Bo"

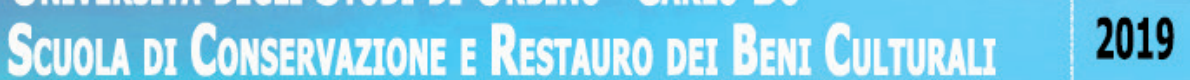

\section{The retouching on archaeological metal artifacts: reflections and proposals, between theory and practice}

\author{
Vilma Basilissi, Simona Pannuzi, Laura Rivaroli
}

\begin{abstract}
When the restoration of archaeological metal artifacts is considered, the reconstruction and chromatic treatment of the gaps often determine the correct reading of the object, by suggesting its original morphology and external coloring as linked to the degraded surfaces. However, for such a kind of artifact, it is particularly frequent to deal with a remarkable diversity of reconstructions and integrations related to conceptions usually based on opposing principles ranging from mimetic integrations up to a strict rigorism. The purpose of the present work is to contribute to the definition of a conservative intervention protocol based on the reversibility to get a correct and widely perceptive presentation of the restoration work for this kind of artifacts, aimed at their formal reconstruction and aesthetic retouching.
\end{abstract}

Keywords: metallic artifacts, retouching, reintegration, texture, gaps

\section{Retoques en artefactos metálicos arqueológicos: reflexiones y propuestas, entre la teoría y la práctica}

Resumen: Cuando se considera la restauración de artefactos metálicos arqueológicos, la reconstrucción y el tratamiento cromático de las lagunas generalmente determinan la lectura correcta del objeto, lo que sugiere su morfología original y el color externo asociado con las superficies degradadas. Sin embargo, para tales artefactos, es particularmente común tratar con una notable diversidad de reconstrucciones e integraciones relacionadas con concepciones, generalmente basadas en principios opuestos, que van desde la integración mimética hasta el rigor estricto. El objetivo del presente trabajo es contribuir para la definición de un protocolo de intervención conservativa basado en la reversibilidad, para obtener una presentación correcta y ampliamente perceptiva del trabajo de restauración para este tipo de artefactos, con el objetivo de su reconstrucción formal y reintegración estética.

Palabras clave: artefactos metálicos, retoques, reintegración, textura, lagunas

\section{A reintegração em artefatos arqueológicos de metal: reflexões e propostas, entre a teoria e a prática}

Resumo: Quando o restauro de artefactos metálicos arqueológicos é considerado, a reconstrução e o tratamento cromático das lacunas geralmente determinam a leitura correta do objeto, sugerindo a sua morfologia original e a coloração externa associadas às superfícies degradadas. Contudo, para tais artefactos, é particularmente frequente lidar com uma notável diversidade de reconstruções e integrações relacionadas com conceções, geralmente baseadas em princípios opostos, que variam da integração mimética até a um estrito rigor. O objetivo do presente trabalho é contribuir para a definição de um protocolo de intervenção conservativa baseado na reversibilidade, para obter uma apresentação correta e amplamente percetiva do trabalho de restauro para este tipo de artefacto, visando sua reconstrução formal e reintegração estética.

Palavras-chave: artefatos metálicos, retoque, reintegração, textura, lacunas 


\section{Introduction}

In the restoration of metal artifacts from archaeological excavations, the formal reconstruction and the chromatic treatment of the gaps - "lacunas" - determine, sometimes decisively, the correct reading of the object suggesting its original and complete morphology. Furthermore, in doing it, another important issue concerns the perception of the external coloring of the degraded surfaces. In the case of the restoration of this kind of artifacts, many different interventions of reconstruction, integration, and restitution have been developed and proposed. They are based on opposing principles that range from mimetic integrations up to a clear indication of the new fillings of the gaps. According to the latter procedure, which sometimes exploits questionable executive solutions, gaps should be treated by underlining the "compensated parts" through volumetric restitution characterized by a slight sub-level and by subdued chromatic restitution compared to the original surface of the artifact.

In the conservation field, the latin term lacuna meaning an emptiness or a loss of the pictorial surfaces (paintings on walls, canvas, and tables) or a gap of colour and volume (stone sculpture, metals, wooden sculpture, ceramics and complex artifacts such mosaics, tapestries, textiles, jewelry) ${ }^{[1]}$. In the conservation terminology, a lacuna is properly related to a surface interruption which is distinctly circumscribed, clearly distinguished from mancanza, an Italian word that namely the partial or total lack of an element. A lacuna produces a disturbance not only in the area where it is located but often along with the entire artwork which, in the visual perception of the artifact, means that a lacuna proceeds forward while the artwork moves backward. Therefore, a correct restoration must bring back the lacuna to ensure a correct visual perception of the object ${ }^{[2]}$.

To guarantee the integrity of the artifact, the clear readability of the original shape and the minimum modification of the surface, a detailed intervention project has to be defined before starting the operativity of the conservative restoration.

The various conservation conditions of artifacts and the different characteristics of morphology, size, and distribution of lacunas, are the main features to consider when choosing among the different kinds of integration. Therefore, it is definitively needed a careful evaluation of when and how to integrate and the best products to be used, as clarified in the proposed case studies.

According to the above, we aim to define a conservative intervention protocol for this kind of artifacts, shared by restorers, archaeologists, and art historians and based on a correct and widely perceptive presentation. The goal of a comprehensive conservative and restoring intervention is to achieve the stability and the maintenance of the artwork, with a reversible reconstruction of its morphology and an aesthetic retouching that allows restitution as close as possible to the original artwork.

According to these guidelines, on the base of archaeological and typological research, it is also possible to make different proposals of reversible solutions that are more or less extensive and complete to reconstruct the original shape and surface of the artifact, for instance by working on the texture and/or the colour. In our opinion, such a critical approach will lead to better and more correct enjoyment of the artwork both for scholars and public visitors.

These theoretical and technical reflections are proposed within a working frame of continuous revision of restoration methodologies.

\section{Some examples of conservative interventions of archaeological metal artifacts}

In recent years, several case studies have been carried out by the ICR Metals Laboratory, thus providing a large number for operative exemplifications as support and optimization of the mentioned issues.

In this paper we present three significant interventions as an example:

- the first case study is referred to as an intervention on an artefact (inv. 516520, SS-ABAP-RM) found in 1998 in the area of the Military Hospital Celio in Rome in 1998 [Figure 1]. Initially, the artefact was supposed to be an iron container, but even at the end of the restoration it was not possible to clearly define its functional use ${ }^{\left[{ }^{[3]} \text {; it }\right.}$ arrived at the ICR laboratory covered by the excavation soil and split into 42 fragments;

- the second intervention relates to three elements of an archaic age bronze armour, two greaves and one helmet (inv. 86702, SABAP-MAR), broken in more than 100 fragments [Figure 2], presumably discovered in the area on the border between Marche and Lazio ${ }^{[4]}$;

- the third restoration activity has been carried out on three helmets (inv. 1081, 1083, 1097, SABAP-RMET) differing for typology, technical aspects and conservation conditions [figure 3], all coming from the Becchina legal seizure ${ }^{[5]}$.

By preliminary study and planning of restorations, from the cleaning operations to the stabilization processes, from the reconstruction of the volumes to the perceptual integration of the lacunae, these three case studies allowed to infer important theoretical and technical considerations on the physical and aesthetic restoration of archaeological metal artifacts. All those works were developed along with the didactical courses of the ICR school. 


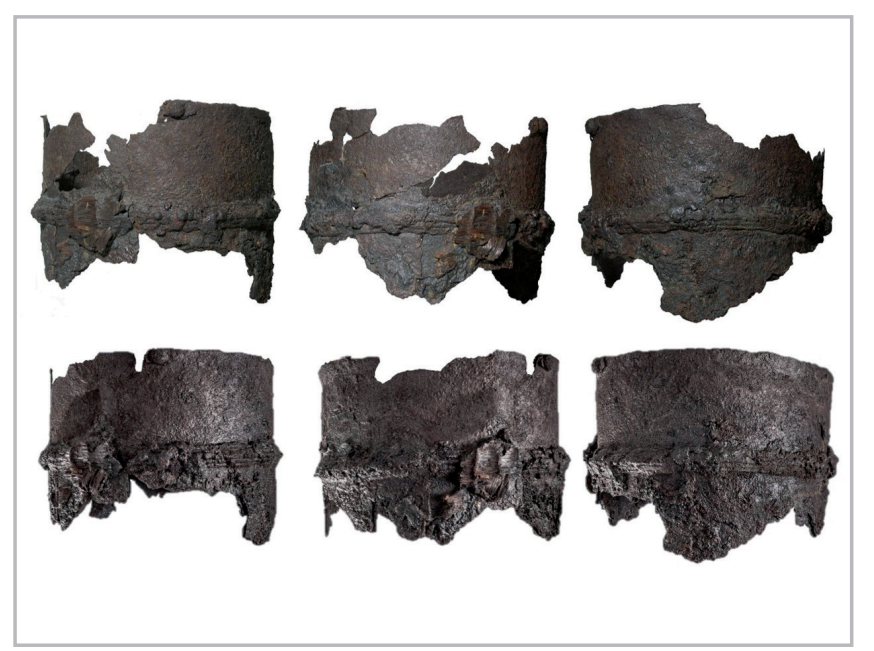

Figure 1.- The iron artefact (inv. 516520, SS-ABAP-RM) before and after the formal and aesthetic integration

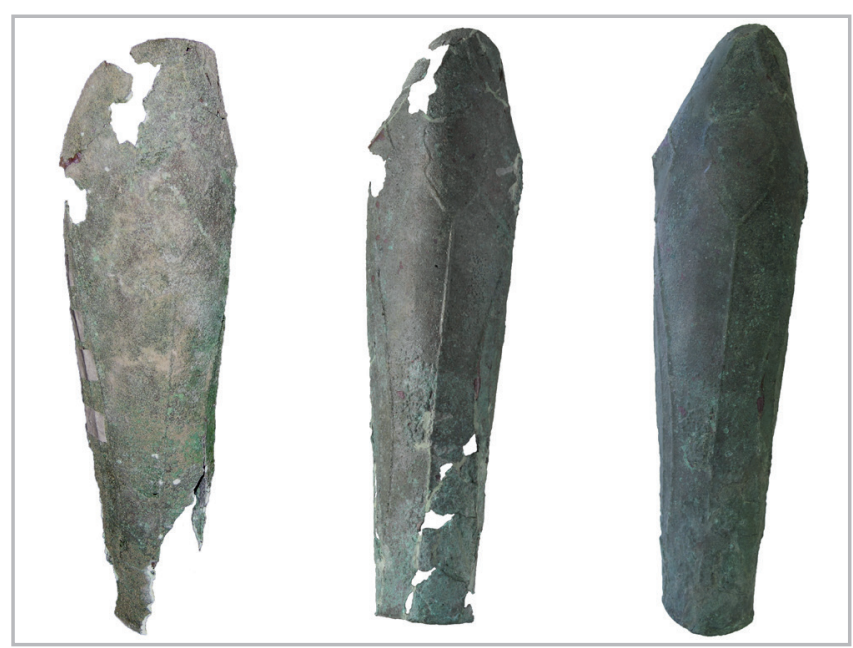

Figure 2.- Greave (inv. 86702, SABAP-MAR) of bronze armour of archaic age, before and after the formal and aesthetic integration

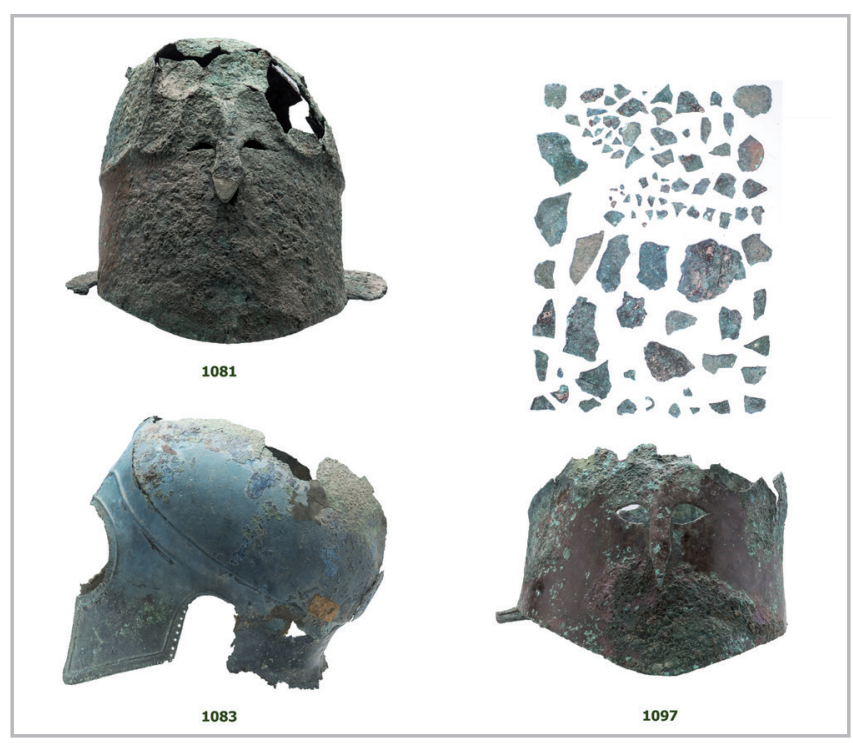

Figure 3.- The bronze helmets (inv. 1081, 1083, 1097, SABAP-RMET) before restoration
A large amount of fragments preserved, especially in the case of the iron artifact and the bronze helmets, has required a continuous and meticulous checking of the cleaning level which has allowed to conduct a typological comparison with similar artifacts, eventually identifying technological and formal details that otherwise could be neglected. After the surface cleaning phases and the temporary reconstruction of the forms, the artifact volume can be fully defined, thus allowing a correct approach to the problem of the gaps and their integration.

The altered artefacts surfaces have suggested the integration fillings, in a similar way to what suggested by the theoretical approach, even if the different technical features of artefacts must be accounted. In fact, in metals, unlike other materials, formal deformations can occur and it is not always possible to find the original surface due to corrosion.

The main goal of such a process is matching the integrations to the artefact surfaces, respecting the principle of recognition of intervention, by focusing the filling treatments both on their texture (for the iron object) and their chromatic balancing (copper alloy artefacts).

The iron artefact had a very irregular surface characterized by a chromatic uniformity, with strongly opaque, dark brown fragments and gaps of medium/small extension. Conversely, the bronze findings had a partially smooth surface, characterized by the presence of chromatically heterogeneous corrosion crusts, of constant and opaque thickness and medium/large gaps.

Among the fundamental requirements for the choice of the products to be used, there has been the evaluation of their workability time and easy vertical application, as a necessary characteristic for the realization of integrations. Another important feature is that resins must be completely compatible with each other, thus allowing their combined utilization, according to the specific requirements of the conservative intervention. The restitution of the form was carried out by deepening and testing new materials, but in this case, we want to focus on the issue of the aesthetic integrations.

The iron artefact was characterized by an irregular surface that showed the degradation phenomena caused by a fire. Being the artefact incomplete, the correct reading of the object was invalidated. Usually, resins selected for formal compensations are coloured pastes, as closely as possible to the colours of the altered constituent material. For the iron artefact, assembled and recomposed, was exploited a specific treatment of the integrated gaps by using a thixotropic resin which is optimal for the final result of the texture integration. In fact, spread in several layers, its hardening speed allows the vertical application and the quick workability with brushes and spatulas [Figure 4].

Even the conservative intervention of the bronze findings has utilized the same methodology usually employed 


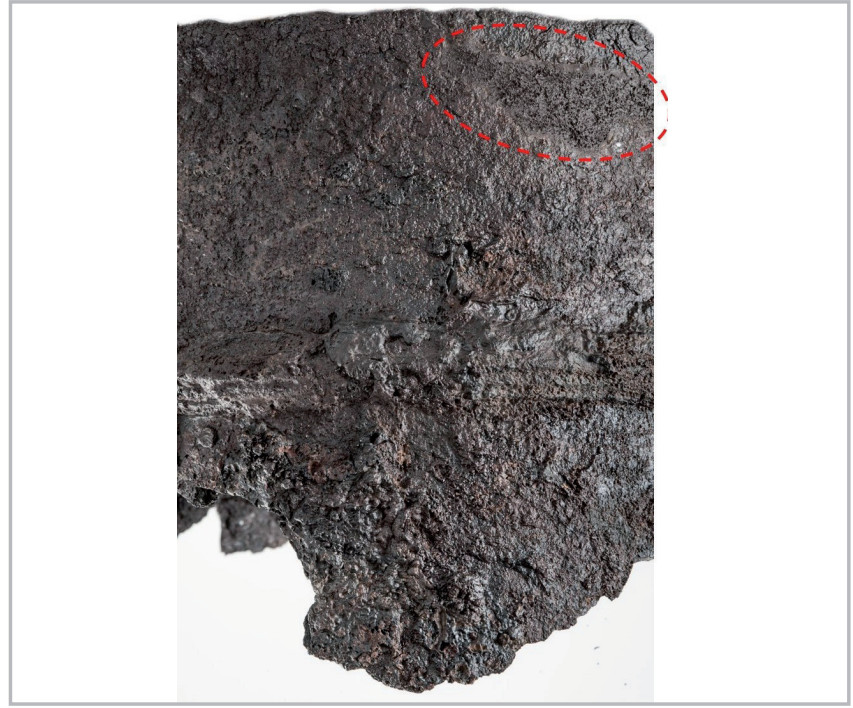

Figure 4.- Detail of the texture of the integration by applying the resin on the previous filled gap (inv. 516520, SS-ABAP-RM).

for the formal integrations, but the these have been chromatically balanced using pure colours by means of the addition of small dots (i.e. a sort of chromatic pointillism). Restoration parts have been tuned to the original surface of the findings so as to allow the artefacts are restored at the greatest level of integrity, at the same time respecting the principle of recognizing the intervention. In fact, a close view of the surfaces highlights the areas of the integrations, characterized by a specific texture of the colour points and conferred by the brush with a spraying application technique, bringing them to a level of optical perception different from the original metal surface.

\section{Reflections on criteria and methods for retouching integrations of archaeological metal artefacts}

The theoretical and technical reflection, already widely focused in the reconstruction and realization of formal and perceptive integrations on archaeological findings, in particular on ceramic ones [7, 8, 9, 10], is presently under a process of revision for what concerns those methods of integrative restoration applied for a long time on metals. They are often referred to very general principles that, although precise, seem to be insufficient to establishing a protocol for a methodology of integration on archaeological metals in a close relationship with the specificity of the single intervention

Projecting the executive intervention means to establish in advance "if and how" acting to bring the object back to its unity of shape and surface [Table 1]. However, when it is planned to integrate the gaps of the metallic archaeological findings, it is needed to re-establish some methodological criteria in the approach to conservative intervention.

The fundamental criteria to be adopted during the conservative restoration are: 1) the recognition of interventions; 2) the reversibility of procedures; 3 ) the compatibility with the original; 4) accurate documentation. Moreover, some integrations can be added in three main cases: 1) when there is a structural need for the object (structural requirements); 2) when there is an advantage for the study of the shape (formal compensation); 3) for the purpose of a better and more adequate perceptive reading of the artifact (aesthetic presentation).

Table 1.- Suggested protocol for integrations on archeological metal artefacts

\begin{tabular}{|c|c|c|c|c|}
\hline & & & theoretical goals & products suitable \\
\hline \multirow{6}{*}{ 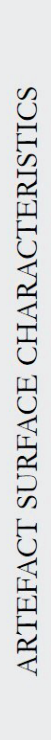 } & \multirow{4}{*}{ 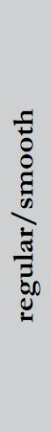 } & \multirow{2}{*}{ chromatically uniform } & \multirow{2}{*}{$\begin{array}{c}\text { Colored epoxy resin } \\
\text { (formal compensation and aesthetic } \\
\text { presentation) }\end{array}$} & $\begin{array}{c}\text { UHU plus Endefest } 300 \text { coloured by artist } \\
\text { pigments }\end{array}$ \\
\hline & & & & $\begin{array}{c}\text { ARALDITE LY544 coloured by epoxy } \\
\text { colorant }\end{array}$ \\
\hline & & \multirow{2}{*}{ chromatically uneven } & \multirow{2}{*}{$\begin{array}{c}\text { Colored epoxy resin }+ \text { chromatic } \\
\text { integration of texture (formal compensation } \\
\text { and aesthetic presentation) }\end{array}$} & $\begin{array}{c}\text { UHU plus Endefest } 300 \text { coloured by artist } \\
\text { pigments + varnish colours/ acrylic } \\
\text { colours/Gamblin colours }\end{array}$ \\
\hline & & & & $\begin{array}{c}\text { ARALDITE LY544 coloured by epoxy } \\
\text { colorant }+ \text { varnish colours/acrylic colours } \\
\text { /Gamblin colours }\end{array}$ \\
\hline & \multirow{2}{*}{ 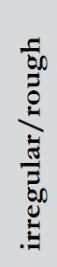 } & chromatically uniform & $\begin{array}{c}\text { Colored epoxy resin } \\
\text { (formal compensation and aesthetic } \\
\text { presentation) }\end{array}$ & ETOBOND 6066 coloured by artist pigments \\
\hline & & chromatically uneven & $\begin{array}{l}\text { Colored and treated epoxy resin }+ \\
\text { chromatic integration of texture (formal } \\
\text { compensation and aesthetic presentation) }\end{array}$ & $\begin{array}{c}\text { ETOBOND } 6066 \text { coloured by artist pigments } \\
+ \text { varnish colours/acrylic colours/Gamblin } \\
\text { colours }\end{array}$ \\
\hline
\end{tabular}


Nevertheless, a few problems remain open. In fact, not all spaces are recoverable: in correspondence with areas of strong mechanical deformation or where the presence of functional or decorative elements is presumable, it may be more complex to find a form and surface restitution agreement.

In this case, it must be established whether to recover the missing part, for better use and understanding of the original object, or not. Such a procedure can be adopted only if the proposed intervention is completely reversible and of minor impact on the object (low mechanical stress). When the integration of empty spaces is performed, there are a couple of different conditions of the artefact to take into account: 1) the surface does not exhibit any graphical signs or, inversely, 2) on the surfaces there are figurative elements.

In the former case, the utilization of filling reversible materials is required, selected by accounting for specific cases related to the main methods of returning the object: for a material compensation of the gaps, with a formal integration of the volumes; for a chromatic balancing of the surfaces, and integration with the treatment of the texture [Figure 5, a-b]. In this framework, it is therefore required to evaluate which kind of reversible material to choose for formal and aesthetic integrations, which kind of colors to use and if a minimum sub-level of the integrations is also needed.

In the latter case, when figurative details are present on the surface, the problem is much more complex and a careful analysis of various aspects is needed [Figure 5, c]. Possible solutions are to avoid a direct intervention on the deficiencies or operating on their optical return, for example by using support inside the object that formally compensates the gap and suggests the missing figurative part.

\section{Conclusions}

In conclusion, the integration of archaeological metal artifacts and related technologies is a subject to be carefully evaluated, as it is still treated in many cases with different and, at the same time, opposite methodologies. Indeed, the possibility of reconstruction, functional to the correct vision and enjoyment of the artwork, is usually underestimated and the choice of the aesthetic presentation methodologies of the archaeological artifacts is often treated as a secondary element concerning their volumetric reconstruction.

In principle, the most important issue in the restoration of the metal artifacts concerns if to fill the gaps, with which modality, restoration products and chromatic features of the integrated surface.

In this study, we have attempted to contribute to the definition of a conservative intervention protocol based on a correct, reversible and widely perceptive presentation of the restoration work for this kind of artifacts, for their formal reconstruction and aesthetic retouching, aimed at its best fruition thanks to critical restitution, ever reversible, that really points to the "return to unity", as indicated by Cesare Brandi.

\section{References}

ANGELUCCI, S. (2006). "Materia come "struttura" e materia come "aspetto". Dalla teoria alla prassi". In La Teoria del restauro nel Novecento da Riegl a Brandi, Andaloro, M. Firenze: Nardini, 285-294.

BANDINI, G. (1992). Forma e immagine: ossia considerazioni sul problema delle lacune nelle ceramiche, Faenza, n.o 78, 3-4: 223-230, LIII-LV.

BASILISSI W., GIOMMI M., GUIDA G., MARIOTTINI M., PANNUZI S. (2016). "(Ri)portati alla luce: gli armamenti del guerriero. Nota preliminare sull'intervento conservativo ISCR su elementi di armatura in bronzo di epoca arcaica". In Dalla Valdelsa al Conero. Ricerche di archeologia e topografia storica in ricordo di Giuliano De Marinis, Baldini, G. and Giroldini, P. (coord.). Firenze: All'Insegna del Giglio, 415-419.
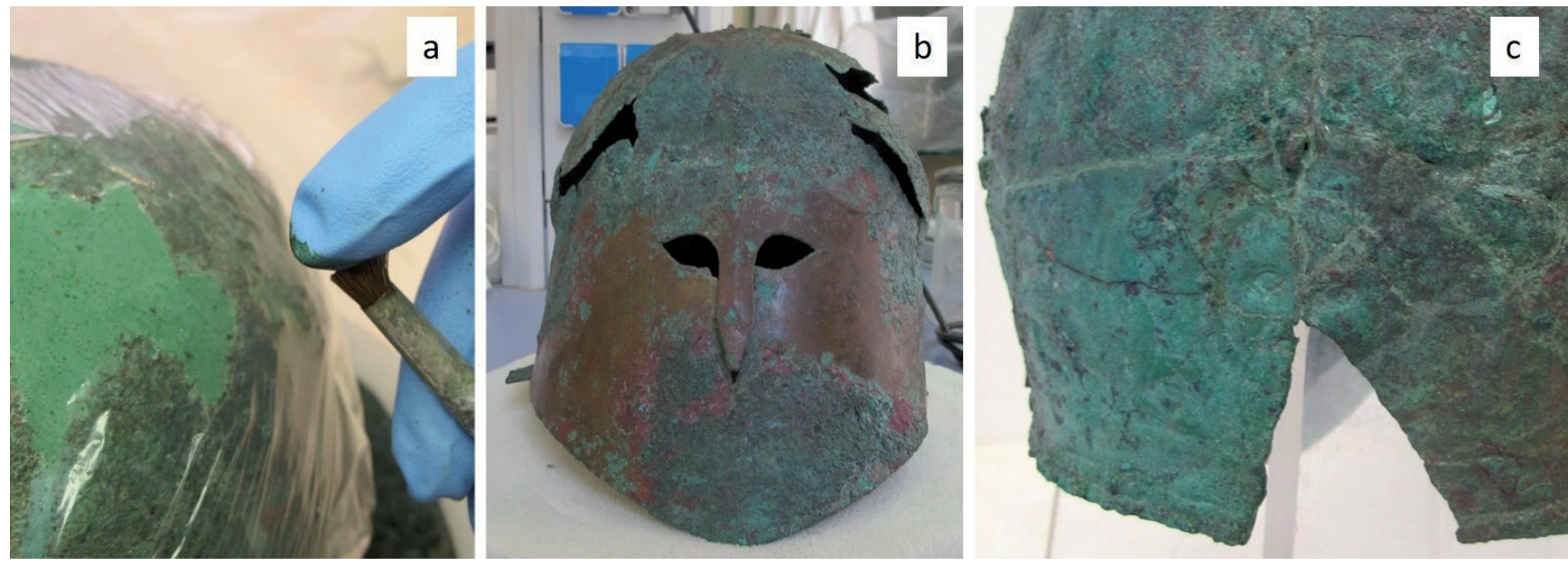

Figure 5.- Bronze helmet (inv. 1097, SABAP-RM-ET) with a formal integration of the volumes and chromatic balance of his surfaces (a-b). The bronze helmet (inv. 86700, SABAP-MAR) has a missing figurative part that is not yet integrated pending further critical reflections (c). 
BASILISSI, W. (2013). "Un reperto metallico dallo scavo del Padiglione 18. L' intervento conservativo". In Gli dei propizi. La Basilica Hilariana nel contesto dello scavo dell'Ospedale Militare Celio (1987-2000), Palazzo, P. and Pavolini C. (coord.). Roma: EDIZIONI QUASAR, 372-375.

BRANDI, C. (1977). Teoria del restauro. Torino: Einaudi.

CAGNINI, A., DE MARCO, M., GALEOTTI, M., MICHELUCCI, M., SORELLA, F. (2006). "Lacuna e integrazione nelle ceramiche archeologiche. Proposte e sperimentazioni in odor di eresia nel restauro di un cratere apulo a figure rosse del Museo di Fiesole", OPD Restauro, n.018: 164-176, https://www.jstor.org/stable/24395041.

D'ERCOLE, V. (2019). "CATALOGO. Sezione 5. The valour of the warrior. Schede Catalogo 110,111,112". In Colori degli Etruschi Colors of the Etruscans. Tesori di terracotta alla Centrale Montemartini - Terracotta treasures at the Centrale Montemartini, Roma: Gangemi, 215-216.

GAETANI, M. C. (2006). "La reintegrazione delle lacune attraverso la tecnica del tratteggio: Considerazioni sul metodo. Dalla teoria alla prassi". In La Teoria del restauro nel Novecento da Riegl a Brandi, Andaloro, M. Firenze: Nardini, 277-284.

GIANNINI, C. (coord.) (2010). Dizionario del restauro. Tecniche diagnostica conservazione, Firenze: Nardini, 96.

MELUCCO VACCARO, A. (1989). Archeologia e restauro. Milano: ॥ Saggiatore.

\section{Author/s}

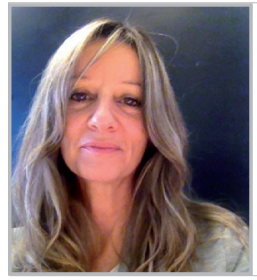

\section{Vilma Basilissi}

vilma.basilissi@beniculturali.it

Institute of restauration, Rome (ICR)

Vilma Basilissi is graduated and specialized at ICR of Rome in 1996. From the 2002 she is a restorer focusing in conservation and restoration of metal and alloy artefacts at the Institute of restauration (ICR) of Rome and lecturer at the ICR High School (SAF ICR).
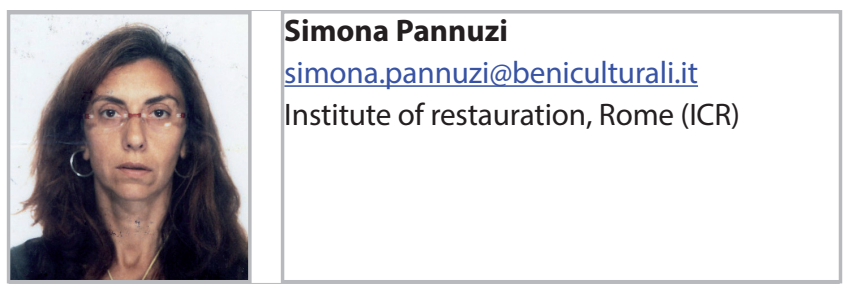

Simona Pannuzi is graduated and specialised in Medieval Archaeology at the University of Rome "La Sapienza". For almost twenty years has been functionary archaeologist of the Italian Ministry of Culture and she worked in the Archaeological
Superintendence of Ostia. Actually in ISCR she is the Director of some researches about polychromy and gilding on the Italian and medieval and renaissance sculptures, also with the collaboration of the Czechoslovakian University of Olomouc, the research about polychromy and gilding of the Gandharan sculptures in collaboration with various partners and Sostituire dopo "and the": conservation and restauration projects on artworks of different materials (e.g. metals, stuccos, stones, frescos).

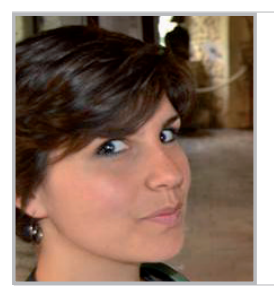

\section{Laura Rivaroli}

laura rivaroli@yahoo.it

Freelance, Roma

Laura Rivaroli is a restorer of artefacts in metal, ceramics and other materials. She graduated from the ICR of Rome in 2010 and works free-lance for private and public commissioners. She is vice president of YOCOCU (Youth in Conservation of Cultural Heritage). 